\title{
Current Understanding of Proton Conduction in Confined lonomeric Systems
}

\author{
Shudipto K. Dishari* \\ *Chemical Engineering, The Pennsylvania State University, University Park, Pennsylvania 16802, USA. \\ *E-mail: skd19@psu.edu
}

\begin{abstract}
Ion containing polymers, when confined into several $\mathrm{nm}$ to several hundreds of $\mathrm{nm}$ thick films, behave very differently from bulk membranes. Understanding the proton transport mechanism in thin ion containing polymer (ionomer) layers coated over catalysts is crucial for further improvement of proton exchange membrane fuel cell (PEMFC) performance. In thin films, the proton conduction properties may not be governed by the amount of water sorbed. Water molecules in such systems experience strong confinement, behave like bound immobilized water and fail to create percolated active proton conduction pathways. Therefore, in confined ionomeric systems, some factors other than water uptake need consideration to clearly understand the observed proton transport. These factors include solvation of ionic groups of polymer, local concentration of proton $\left(\mathrm{H}^{+}\right)$, connectivity of hydrophilic domains, and, orientational relaxation dynamics of water.
\end{abstract}

\section{Introduction}

Understanding of nanoscopic water is of fundamental importance in hydrated polymeric systems. Ion containing polymers (ionomers) have potential applications in energy conversion applications, optoelectronic devices, biomedical applications, food industries and so on. In proton exchange membrane fuel cells (PEMFCs) (Figure 1a), a thin layer $(\sim 2-100 \mathrm{~nm})^{1,2}$ of ionomer is coated over the carbon supported Pt catalyst layer at cathode (Figure 1 b). In addition to

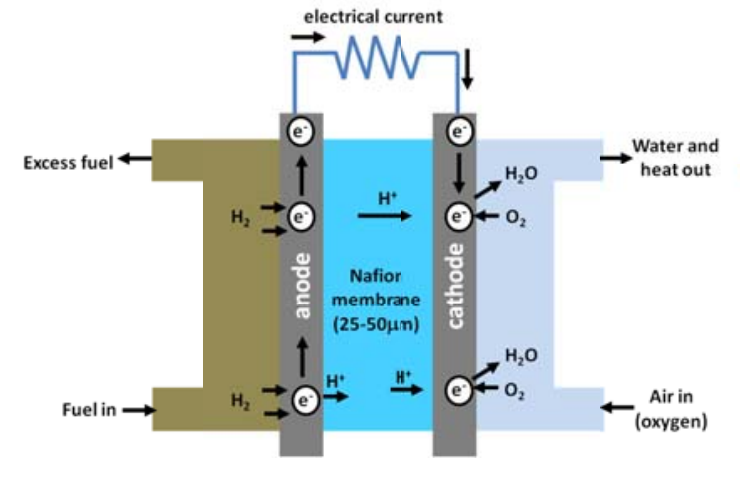

(a)

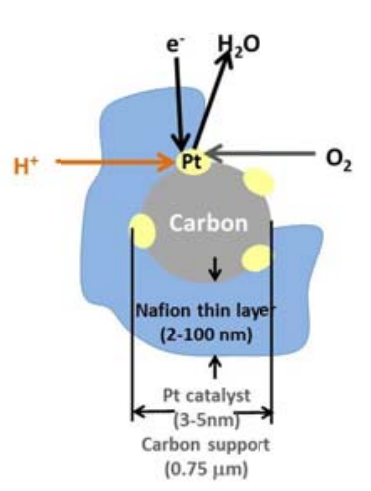

(b)

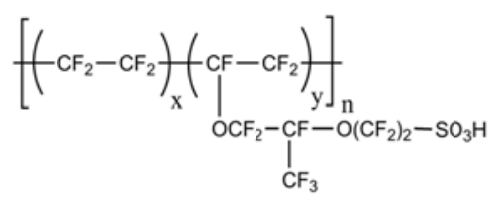

(c)

Figure 1. Schematic of (a) proton exchange membrane fuel cell (PEMFC) and (b) a cathode catalyst site; (c) structure of perfluorosulfonic acid based ionomer, Nafion. 
placing a proton conducting Nafion (Figure 1c) or other ionomer membrane in between two electrodes, the purpose of depositing this thin ionomer layer over catalyst is to improve catalyst binding, promote proton conduction at catalyst active sites and enhance the oxygen reduction reactions. However, very little is known about transport properties of thin ionomer films. With a cost target of $\$ 30 / \mathrm{KW}$ for fuel cell based automobiles, it is crucial to develop the basic understanding of thin supported ionomer films at hydrated state. The insights gained through these studies can be very helpful in optimizing the design of ionomer-catalyst interface for improved proton conductivity.

In many ways, bulk films and membranes are different from thinner films. ${ }^{3,4}$ Confinement of polymer chains, water molecules and protons $\left(\mathrm{H}^{+}\right)$in thin films is predicted and proved using a number of complementary surface characterization techniques. ${ }^{4,5,6}$ Confinement restricts the rotational motion of water molecules, a crucial step for forming $\mathrm{H}$-bonded water network and conducting protons. As a result, thin films encounter higher ionic resistance and suppressed proton conductivity $^{5,7,8}$ over corresponding membrane counter parts. This review paper covers the current understanding and perspective of thin ionomer films for PEMFCs in terms of proton transport. The factors affecting the proton transport in confined thin films are discussed with indications of potential future scopes of work in this area.

\section{Techniques to measure proton transport}

Most of the research works report proton conductivity measured by impedance spectroscopy technique. In this technique, microelectrodes ( $\mathrm{Pt}, \mathrm{Au}$ etc) are strategically deposited as interdigitated array (IDA). Impedance is measured under an applied potential over range of frequencies. The impedance response is then fitted to obtain resistance $\left(R_{f}\right)$. Using this resistance value along with the known distance between electrodes (d), length of teeth (I), number of electrodes $(\mathrm{N})$, and, film thickness $(\mathrm{t})$, proton conductivity $\left(\kappa_{f}\right)$ is calculated as follows: ${ }^{5}$

$\kappa_{f}=\frac{1}{R_{f}} \frac{d}{I(N-1) t}$

Apart from direct measurements of proton conductivity values, efforts have been given to gain basic understanding of proton transport using fluorescence based techniques. Fluorescence is a very sensitive technique and can thus offer important insights about the protonic microenvironment inside thin films. The existing understanding on connection between hydration and state of confined water, when considered to explain the fluorescence data, offers an array of information about the local proton concentration, water pool size and extent of proton transfer. These studies rely on photoacidic probes, also known as excited state proton transfer (ESPT) probes. ${ }^{9}$

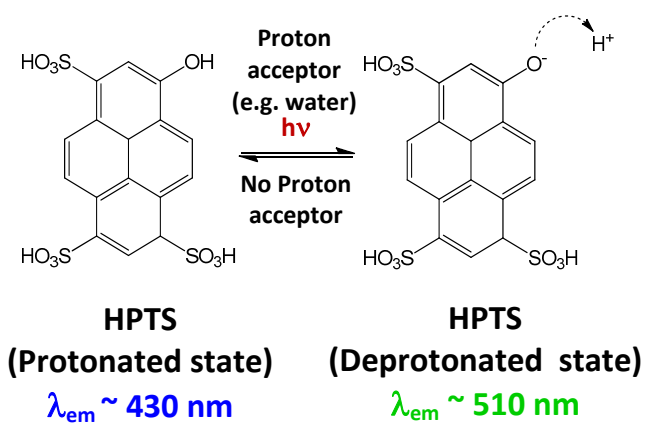

Figure 2. Structure of photoacidic probe HPTS at protonated and deprotonated state.

The uniqueness of these probes is their abrupt change in acid dissociation constant $\left(\mathrm{pK}_{\mathrm{a}}\right)$ upon photoexcitation. While an ESPT probe, like, 1hydroxy-3,6,8-pyrenesulfonic acid (HPTS, Figure 2) possesses a $\mathrm{pK}_{a}$ value of 7.7 at ground state, its phenolic group gets deprotonated upon photoexcitation immediately as the $\mathrm{pK}_{\mathrm{a}}$ drops to 0.7. ${ }^{9}$ However, the dye can retain its deprotonated state only if it gets proton acceptors, like water molecules around it to take the proton away from the deprotonation site. Therefore, it behaves the same way as any 

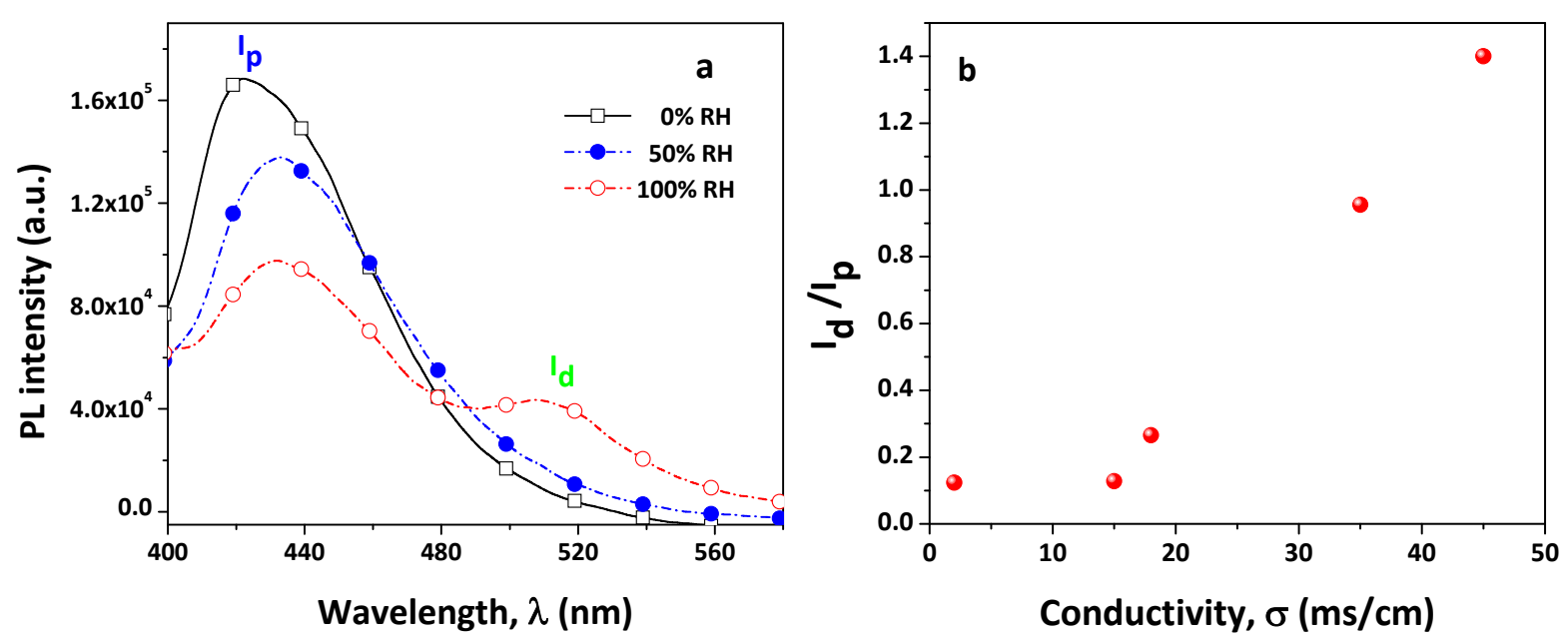

Figure 3. (a) Fluorescence intensity of HPTS in a $590 \mathrm{~nm}$ thick Nafion film on $\mathrm{SiO}_{2}$ surface $\left(\lambda_{\text {exc }} 370 \mathrm{~nm}\right.$, $\lambda_{\text {em }} 400-590 \mathrm{~nm}$ ) as a function of relative humidity (RH); (b) Ratio of fluorescence intensities of deprotonated to protonated state $\left(I_{d} / I_{p}\right)$ as a function of proton conductivity $(\sigma)$ in Nafion membrane (data taken from ref ${ }^{4}\left(\mathrm{PL}\right.$ intensity and $I_{\mathrm{d}} / I_{\mathrm{p}}$ ) and ref ${ }^{10}(\sigma)$ ).

sulfonic acid $\left(-\mathrm{SO}_{3} \mathrm{H}\right)$ functionalized ionomer (e.g. Nafion) in an aqueous environment. By tracking the fluorescence of deprotonated state $\left(I_{d}, \lambda_{\text {em }}\right.$ $\sim 510 \mathrm{~nm})$ and protonated state $\left(I_{p}, \lambda_{\text {exc }} \sim 430 \mathrm{~nm}\right)$, the extent of proton transport are estimated (Figure 3a). ${ }^{4}$ Deprotonation ratio $\left(I_{d} / I_{p}\right)$ gives information similar to proton conductivity ${ }^{10}(\sigma)$ as can be seen in Figure $3 \mathrm{~b}$ for bulk nafion membrane. Therefore, $I_{d} / I_{p}$ can be an indirect measure of proton conductivity.

\section{Factors controlling proton conductivity}

Film thickness, substrate and film processing condition effect

Figure 4 shows proton transport trends of spincoated Nafion films as a function of film thickness and $\mathrm{RH}$. The extent of proton transport decreases as the films get thinner. ${ }^{4}$ Proton transport requires sufficient water molecules around proton donating groups (e.g. $-\mathrm{SO}_{3} \mathrm{H}$ ) of ionomers for effective solvation. The water molecules must also be mobile enough to carry the protons away from the site of proton generation. Water gets more and more confined with the decrease in film thickness.

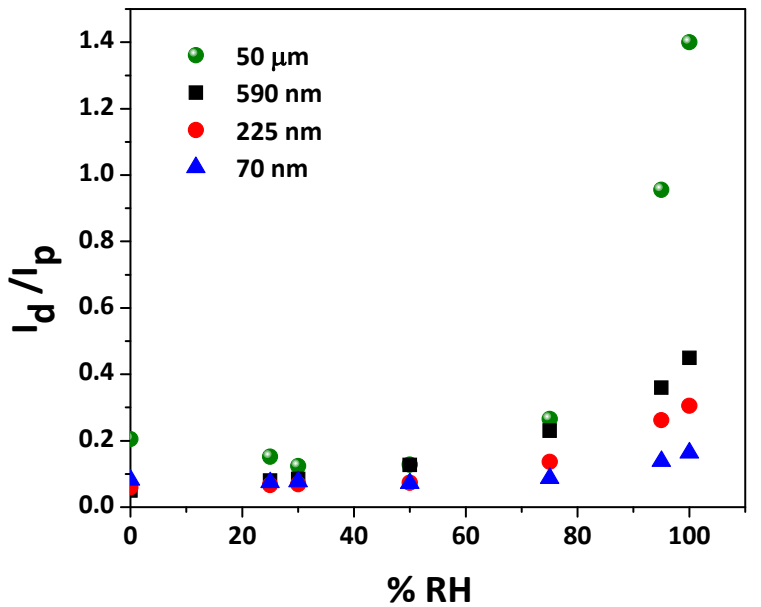

Figure 4. $I_{d} / I_{p}$ of HPTS in spin-coated Nafion films (on $\mathrm{SiO}_{2}$ ) and free standing Nafion membrane as a function of relative humidity $(\mathrm{RH})$ and thickness (data taken from ref ${ }^{4}$ ).

Inadequate solvation $(\lambda \leq 4 \text { at } \mathrm{RH}<50 \%)^{4}$ by highly confined water leads to poor proton conduction in thinner films as compared to bulk membranes. It is interesting to observe a $70 \mathrm{~nm}$ thick Nafion film to uptake more water $(\lambda \sim 11)$ as compared to films with thickness ranging from $150 \mathrm{~nm}(\lambda \sim 6)$ to $600 \mathrm{~nm}(\lambda \sim 5)$ at water activity of $1 .{ }^{4,6} \mathrm{~A}$ higher water content should lead to 
Table 1: Proton conductivities of nafion thin films deposited and processed under varied conditions.

\begin{tabular}{|c|c|c|c|c|c|c|c|c|c|}
\hline$d(n m)$ & Substrate & Electrode & $\begin{array}{c}\text { Film deposition } \\
\text { strategy }\end{array}$ & $\begin{array}{c}\text { Film annealing } \\
\text { condition }\end{array}$ & $\%$ RH & $\lambda$ & $(T)_{\sigma}$ & $\sigma$ & Ref. \\
\hline \multirow[t]{3}{*}{307} & $\mathrm{SiO}_{2}$ (300 nm thermal oxide) & - & Self-assembly & Unannealed & 25 & - & 20 & 2.1 & 7 \\
\hline & & & & & 50 & - & & 15 & \\
\hline & & & & & 95 & - & & - & \\
\hline \multirow[t]{3}{*}{4 to 57} & $\mathrm{SiO}_{2}$ (300 nm thermal oxide) & - & Self-assembly & Unannealed & 25 & - & 20 & - & 7 \\
\hline & & & & & 50 & - & & 0.3 & \\
\hline & & & & & 95 & - & & 19.6 & \\
\hline \multirow[t]{3}{*}{4} & $\mathrm{SiO}_{2}$ (2000 $\mathrm{nm}$ thermal oxide) & $\mathrm{Au}$ & Self-assembly & Unannealed & 20 & 37.5 & 25 & $1.3 \times 10^{-4}$ & 5 \\
\hline & & & & & 40 & 49.2 & & $1.6 \times 10^{-2}$ & \\
\hline & & & & & 85 & 60.1 & & 3.3 & \\
\hline \multirow[t]{3}{*}{10} & $\mathrm{SiO}_{2}$ (2000 nm thermal oxide) & $\mathrm{Au}$ & Self-assembly & Unannealed & 20 & 31.7 & 25 & $2.7 \times 10^{-4}$ & 5 \\
\hline & & & & & 40 & 42.0 & & $1.4 \times 10^{-2}$ & \\
\hline & & & & & 85 & 57.0 & & 4.4 & \\
\hline \multirow[t]{3}{*}{50} & $\mathrm{SiO}_{2}$ (2000 $\mathrm{nm}$ thermal oxide) & $\mathrm{Au}$ & Self-assembly & Unannealed & 20 & 3.9 & 25 & $1.7 \times 10^{-4}$ & 5 \\
\hline & & & & & 40 & 8.6 & & $2.9 \times 10^{-2}$ & \\
\hline & & & & & 85 & 13.9 & & 4.4 & \\
\hline \multirow[t]{3}{*}{160} & $\mathrm{SiO}_{2}$ (2000 nm thermal oxide) & $\mathrm{Au}$ & Self-assembly & Unannealed & 20 & 2.2 & 25 & $1.6 \times 10^{-2}$ & 5 \\
\hline & & & & & 40 & 5.1 & & 0.3 & \\
\hline & & & & & 85 & 12.1 & & 9.9 & \\
\hline \multirow[t]{2}{*}{10} & $\mathrm{SiO}_{2}$ (2000 $\mathrm{nm}$ thermal oxide) & $\mathrm{Au}$ & Self-assembly & Unannealed & 60 & - & 60 & 1.8 & 11 \\
\hline & & & & & 95 & - & & 68.1 & \\
\hline \multirow[t]{2}{*}{10} & $\mathrm{SiO}_{2}$ (2000 $\mathrm{nm}$ thermal oxide) & $\mathrm{Au}$ & Self-assembly & Annealed & 60 & - & 60 & $5 \times 10^{-2}$ & 11 \\
\hline & & & & & 95 & - & & 3.8 & \\
\hline \multirow[t]{2}{*}{260} & Quartz & Pt & Drop-casting & Unannealed & 60 & - & 50 & $1.2 \times 10^{-4}$ & 8 \\
\hline & & & & & 95 & - & & 0.1 & \\
\hline Bulk & Free-standing & - & Casting & Unannealed & 95 & - & - & $10-50$ & 12 \\
\hline membrane & & & & & & & & & \\
\hline$(25 \mu \mathrm{m})$ & & & & & & & & & \\
\hline
\end{tabular}

${ }^{*} \mathrm{~d}=$ Nafion film thickness at dry state; $\lambda=$ Hydration number; $(\mathrm{T})_{\sigma}=$ Temperature $\left({ }^{\circ} \mathrm{C}\right)$ at which proton conductivity was measured; $\sigma=$ proton conductivity $(\mathrm{mS} / \mathrm{cm})$. 
higher conduction of protons. The inverse relationship between proton conductivity and water uptake ${ }^{4,5}$ invokes significant interest and is discussed in a later section in detail. Table 1 presents the literature values of proton conductivity reported for Nafion films with thickness ranging from 4-300 $\mathrm{nm}$ with film processing conditions. The table shows that the proton conductivity at similar $\mathrm{RH}$ can be distinctly different depending on how the films are prepared and what type of substrates are used. The substrate effect on proton conduction is not well-resolved till now. While proton conductivity of a $4 \mathrm{~nm}$ thick self-assembled Nafion film varies just by the variation of oxide layer thickness ${ }^{5,7}$ on $\mathrm{SiO}_{2}$ substrate, it does not show any clear trend with change in substrates in others' work. ${ }^{13}$ The author have found quite similar deprotonation ratio $\left(I_{d} / I_{p}\right)$ for spin coated nafion thin films $(\geq 70$ $\mathrm{nm})$ at similar thickness on $\mathrm{Au}$ and native $\mathrm{SiO}_{2}$ substrates. ${ }^{4}$ Ohira et al. ${ }^{13}$ have obtained a proton conduction trend: $\mathrm{Pt}>$ hydrophilic glassy carbon (GC) > unmodified GC for nafion film thickness lower than $10 \mathrm{~nm}$. The substrate effect on surface current density disappears in films thicker than $10 \mathrm{~nm} .{ }^{13}$ Nafion films prepared by different techniques (self-assembly, drop casting, spin coating) have not been studied at similar thickness so far (Table 1).

While the effect of film preparation conditions on proton conductivity needs further investigation, film treatment conditions have been shown to distinctly affect morphology of the film as well as proton conductivity. Thermal annealing can affect swelling and proton conductivity upon formation of crystalline domains. ${ }^{14}$ Proshad et al. ${ }^{11}$ have shown that annealing causes a transition of the surface of a film from hydrophilic to hydrophobic. The change in both surface wettability $^{11}$ and bulk crystallinity $^{14}$ restricts the water uptake and swelling and leads to lower proton conductivity of annealed films as compared to unannealed ones (Table 1).

\section{Local proton concentration effect}

Abundance of protons and inadequate proton transporting pathways can be detrimental to proton transport. It has been observed that the deprotonation ratio $\left(I_{d} / I_{p}\right)$ does not change significantly up to $75 \% \mathrm{RH}$ in Nafion thin films (Figure 4). Beyond $75 \% \mathrm{RH}$, a large increase in deprotonation is witnessed. By comparing $I_{d} / I_{p}$ of Nafion thin films/membranes ${ }^{4}$ to that of $\mathrm{HCl}$ solutions ${ }^{15}$ with known concentration, one can predict the local proton concentration. Figure 5 shows that proton transport is inversely correlated to proton concentration. A low value of $I_{d} / I_{p}$ and a very high value of proton concentration are observed at low hydration numbers $(\lambda \leq 4){ }^{4}{ }^{4}$ The probability of having water molecules for donation/acceptation of protons is less likely at such a low hydration. Moreover, the water molecules experience much higher degree of confinement in thin films as compared to bulk membranes. As a result, this huge amount of

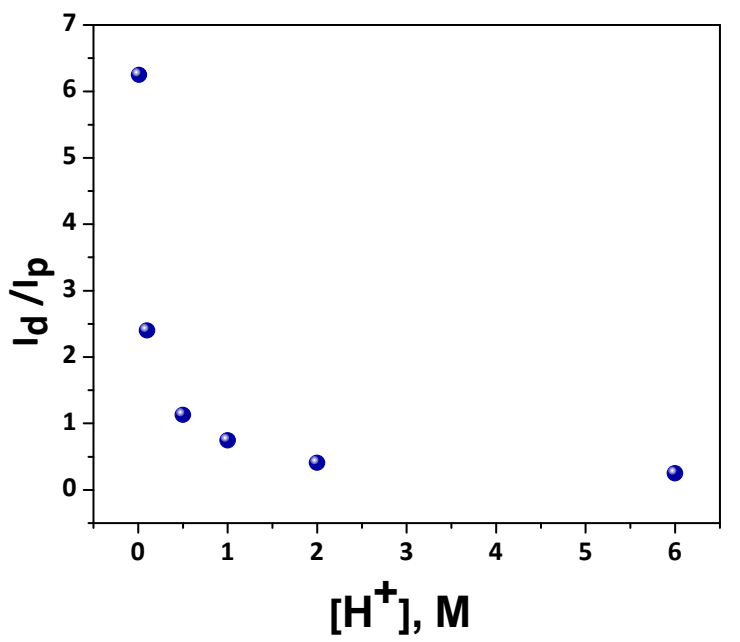

Figure 5. $I_{d} / I_{p}$ of HPTS in Nafion membrane as a function of proton concentration $\left(\left[\mathrm{H}^{+}\right]\right)$. Proton concentrations in Nafion membrane are predicted by comparing the $I_{d} / I_{p}$ values of HPTS in Nafion membrane to those in $\mathrm{HCl}$ solutions with varying acid concentrations (data taken from ref ${ }^{4}$ $\left(\right.$ for $\left.I_{d} / I_{p}\right)$ and $\operatorname{ref}^{15}\left(\right.$ for $\left.\left[\mathrm{H}^{+}\right]\right)$).

protons does not get enough mobile water to diffuse. Thus the deprotonation reaction equilibrium moves towards back-protonation ${ }^{9}$ and proton transport becomes very slow at low $\mathrm{RH}$. While at higher $\mathrm{RH}$, the films swell, water mobility increases to a point where they start to 
percolate to form proton conduction channels. As a result, the local proton concentration drops down and proton conduction is promoted (increase in $I_{d} / I_{p}$ ).

\section{Effect of chemical structure of ionomers}

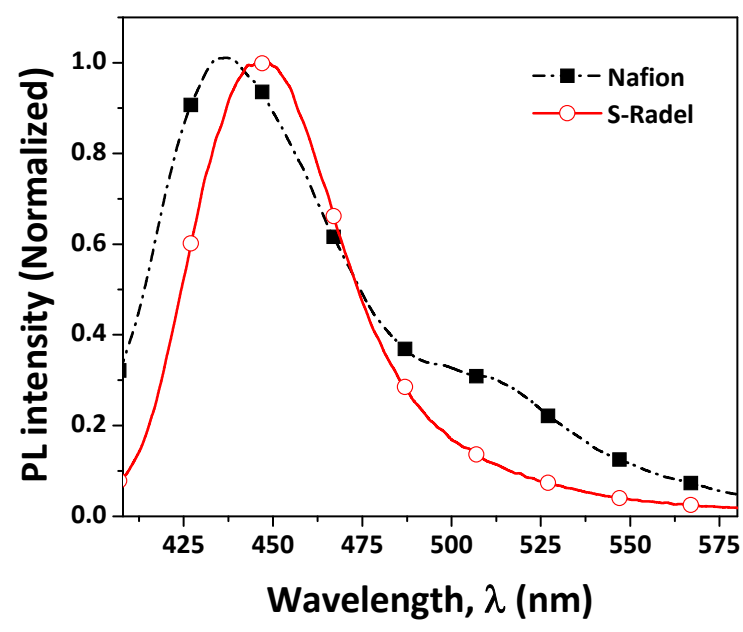

Figure 6. Fluorescence spectra of HPTS in Nafion (घ) and s-Radel (O) films with thickness $~ 200$ $\mathrm{nm}$ at $100 \% \mathrm{RH}$ (Nafion data taken from ref ${ }^{4}$ ).

Alteration of chemical structure of ionomers can influence the film microstructure, state of water and proton conduction properties. While deprotonation of HPTS (rise of fluorescence emission peak at $515 \mathrm{~nm}$ ) is prominent in $200 \mathrm{~nm}$ thick film of perfluorosulfonic based ionomer (Nafion), ${ }^{4}$ no proton transport is observed in a film of sulfonated aromatic ionomer (sulfonated poly (arylethersulfone), S-Radel ${ }^{16}$ here) with similar thickness at $100 \% \mathrm{RH}$ (Figure 6). The distinct differences in proton conduction properties are mainly due to the difference in their acid dissociative nature and phase separation characteristics. Aromatic hydrocarbon based ionomers possess rigid rod like polymer backbone. These ionomers $\left(\mathrm{pK}_{\mathrm{a}} \sim-2\right)$ are less acidic as compared to Nafion $\left(\mathrm{pK}_{\mathrm{a}} \sim-6\right) .{ }^{17}$ The weak proton donating nature is associated with the direct attachment of the sulfonic acid groups to rigid aromatic backbone of S-Radel, making the phase separation difficult. ${ }^{18}$ Due to poor phase separation, water molecules in such systems dwell in disconnected water domains trapped within hydrophobic matrix. Based on small angle X-ray scattering (SAXS) results, Kreuer $^{18}$ has indicated that solid samples of perfluorosulfonic acid based Nafion possess high hydrophilic-hydrophobic phase separation and wide water channels with good connectivity. On the other hand, solid samples of sulfonated poly (etheretherketone) (SPEEK) have narrow water channels with higher tortuosity and dead ends, indicating stronger water confinement. The minimum water volume fraction required for percolation of scattered, ill-connected water channels and facilitation of proton conduction (percolation threshold) is 0.3 for SPEEK, while it is only 0.1 for a Nafion membrane sample. ${ }^{19}$ Moreover, the excess volume of mixing of water with ionomers at corresponding percolation threshold points are $-2 \mathrm{~cm}^{3}$ and $1 \mathrm{~cm}^{3}$ for SPEEK and Nafion, respectively. ${ }^{19}$ The higher percolation threshold and negative volume of mixing again prove the more confined state of water in bulk SPEEK samples as compared to Nafion. Confinement of water, polymer and proton becomes far more severe in the presence of confining interfaces since the behavior of water near an interface is more ice-like. ${ }^{20}$ Therefore, in a supported thin film made of aromatic S-Radel, proton conduction is suppressed due to the added confining surface effect and stronger interfacial interaction (among water-polar groups of polymer-substrate) along with ionomer backbone effect.

\section{Water uptake and water domain connectivity: which one is important?}

The typical ion conduction $(\sigma)$ is function of both the number of charge carrier $\left(n_{i}\right)$ (water is the proton carrier here) and ionic mobility $\left(\mu_{\mathrm{i}}\right)$ :

$\sigma=\Sigma \mathbf{n}_{\mathbf{i}} \times \mathbf{z}_{\mathrm{i}} \times \mathbf{e} \times \mu_{\mathrm{i}}$

where $z_{i}$ is valency of ion carrier, $e$ is the elementary electric charge. ${ }^{21}$ Proton $\left(\mathrm{H}^{+}\right)$mobility is dependent on water rotational mobility. In a bulk hydrated polymer system, water molecules undergo spontaneous orientational relaxation process. ${ }^{22}$ During this relaxation process, water molecules rotate freely and continuously form and break $\mathrm{H}$-bonds with neighboring water 


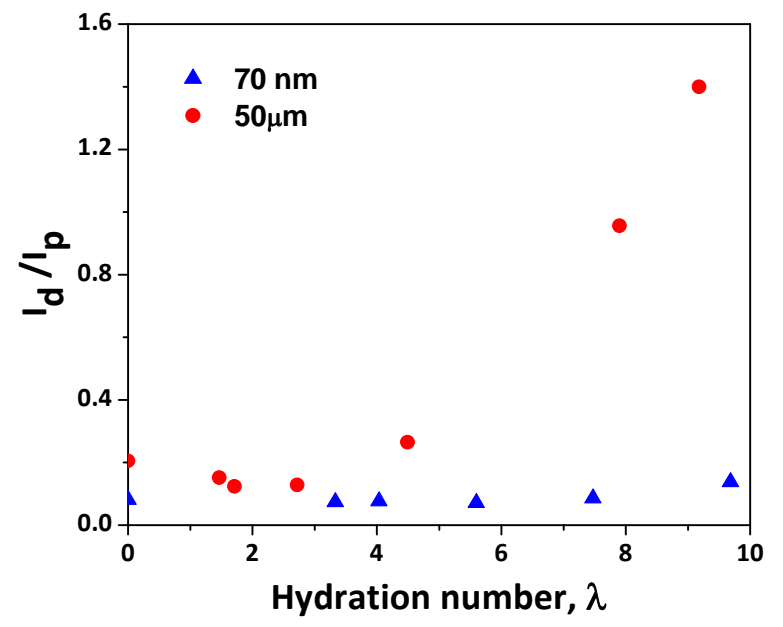

Figure 7. $I_{d} / I_{p}$ as a function of hydration number in a $70 \mathrm{~nm}$ thick Nafion film ( $\mathbf{\Delta}$ ) and $50 \mu \mathrm{m}$ thick Nafion membrane (O) (data taken from ref ${ }^{4}$ ).

molecules. Protons generated at ionic sites of polymers are transported away by these $\mathrm{H}$ bonded water networks. Therefore, proton conduction is considered to be controlled by both water uptake and water mobility, in general. It is interesting to observe that the hydration number at $100 \% \mathrm{RH}$ is similar for both $70 \mathrm{~nm}$ thick film and $50 \mu \mathrm{m}$ thick bulk Nafion membrane (Figure 7). ${ }^{4}$ However, the deprotonation ratio in the film is 10 times smaller as compared to the membrane (Figure 7). ${ }^{4}$ Surface hydrophilicity increases as the film gets thinner which supports the higher level of water uptake of thin Nafion films. ${ }^{23}$ However, the water molecules in thin film are not promoting the proton transport. This supports the fact that proton conduction is not governed by water uptake. The reason behind this decreased proton conductivity from bulk to confined system at similar hydration can be well-understood by close observation of reverse micelle systems with known water domain size (Figure 8).

AOT reverse micelles self-assemble to form core containing hydrophilic sulfonated groups and shell containing hydrophobic tail groups (Figure 8 , inset). The hydrophilic core contains bulk water surrounded by interfacial (interface of bulk

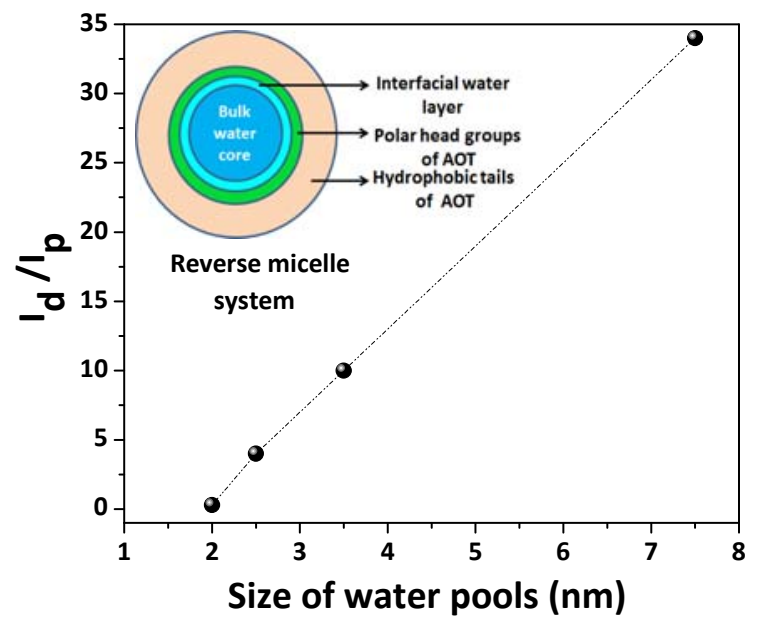

Figure 8. $I_{d} / I_{p}$ as a function of size of water pools in AOT (sodium bis(2-ethylhexyl)sulfosuccinate) reverse micelle system (data taken from ref ${ }^{22}$ (for size of water pools) and $\operatorname{ref}^{24}\left(\right.$ for $\left.I_{d} / I_{p}\right)$ ). Inset shows a schematic of AOT reverse micelle system.

water at core and polar head groups of micelles) water. The deprotonation ratio of HPTS and size of nanoscopic water pool is found to decrease with decreasing size of the reverse micelles (Figure 8). The orientation relaxation is also seen to slow down as the size of the water pools and deprotonation ratio decreases (Table 2). With the decrease in size of reverse micelles (size of water pools <3.5 nm), the water lacks bulk-like characteristics and behaves like interfacial confined water. That is why the orientational relaxation of water becomes slow and drops drastically when size of water pools are $\leq 1.7$ $\mathrm{nm} \cdot{ }^{22,25}$ Same trend has been seen for vibrational energy relaxation of water in these micelles ${ }^{26}$ indicating gradual increase in water confinement (Table 2). This highlights the importance of size as well as connectivity of water domains for rotational reorganization of water molecules and proton transport in confined system. In fact, the slower water rotational dynamics in hydrated thin ionomer films, induced by water-polymersubstrate interfacial interaction, highly impedes the proton conduction. By comparing the $I_{d} / I_{p}$ values of AOT to those of nafion thin films, it can be predicted that the size of a water pool in 70 
Table 2. Change in properties of AOT reverse micelle systems with size.

\begin{tabular}{|c|c|c|c|c|c|}
\hline \multirow[t]{2}{*}{ System } & \multirow{2}{*}{$\begin{array}{c}\text { Size of water } \\
\text { domains by } \\
\text { dynamic light } \\
\text { scattering }(\mathrm{nm})\end{array}$} & \multicolumn{2}{|c|}{$\begin{array}{c}\text { Orientational } \\
\text { relaxation time of water } \\
\text { by time resolved IR (ps) }\end{array}$} & \multirow{2}{*}{$\begin{array}{l}\text { Vibrational relaxation } \\
\text { time constant (ps) by } \\
\text { mid IR-ultrafast } \\
\text { pump-probe } \\
\text { spectroscopy }\end{array}$} & \multirow{2}{*}{$\begin{array}{c}\text { Deprotonation } \\
\text { ratio }\left(I_{d} / I_{p}\right) \text { of } \\
\text { HPTS by steady } \\
\text { state } \\
\text { fluorescence }^{24}\end{array}$} \\
\hline & & $\begin{array}{c}\text { Core } \\
\text { water }\end{array}$ & $\begin{array}{c}\text { Interfacial } \\
\text { water }\end{array}$ & & \\
\hline Bulk water & 7.5 & 2.6 & 18 & 9 & 34 \\
\hline АOT-10 & 3.5 & 4 & 26 & 10 & 10 \\
\hline АОТ-5 & 2.5 & - & 30 & 15 & 4 \\
\hline АОТ-2 & 1.7 & - & 110 & 20 & 0.3 \\
\hline
\end{tabular}

${ }^{\mathrm{a}}$ The number to the right of AOT represents the ratio $\left[\mathrm{H}_{2} \mathrm{O}\right] /[\mathrm{AOT}]$ in solution.

$\mathrm{nm}$ thick nafion film at $100 \% \mathrm{RH}$ is $<2 \mathrm{~nm}$. The size of the hydrophilic domain in a $100 \mathrm{~nm}$ thick Nafion film has been visualized around $\sim 1 \mathrm{~nm}$ with poor phase separation by bright field TEM. ${ }^{5}$ This proves that not the water uptake, but the confinement induced disruption of water mobility and domain connectivity govern the proton conduction in confined geometry. This also shows that HPTS can predict the size of water domains, local $\mathrm{pH}$ and extent of proton transport accurately.

\section{Concluding Remarks}

Proton conduction in a confined system is highly affected by proton carrier (water) mobility rather than the number of proton carriers (or water uptake). In ionomer thin films, the depression of proton conductivity is a result of poor ion solvation dynamics, extremely high local proton concentration and scattered disconnected water domains with high water confinement. Instead of having a significant number of active, connected proton conducting connected pathways, thin films possess tiny, confined aqueous domains which are very ill-connected. High value of hydration number, $\lambda$ (average number of water molecules around a sulfonic acid group) thus does not necessarily symbolize a highly hydrated and highly proton conducting system. Achieving connected hydrophilic channels at lower hydrophilic volume fraction can be the key to improve proton conductivity.

There is ample scope of work to improve the understanding of proton transport in confined ionomer systems. How the fabrication and surface modification of electrode change the wettability of the film and substrate generates a lot of interest in the fuel cell community. Also the optimum thickness of ionomer layer required to coat catalyst for highest proton conduction can be decided based on structure-property relationships. Therefore, investigation of proton transport by systematic variation in film preparation and processing conditions and substrate for a range of film thickness is required. The studies will help develop a comparative database of thin film properties. Also conductivity should be investigated both in-plane and out-of-plane direction. Conductivity values are not expected to be the same in both directions and so far mostly in-plane conductivities are measured for Nafion thin films. ${ }^{5,7,8,11}$ The understanding of thin films can reach to a new level if proton conductivity at different interfaces can be derived since water volume fractions vary widely along the thickness of the film. ${ }^{27}$ These understandings are crucial for future designing of ionomer-catalyst layers.

\section{Acknowledgement}

The author acknowledges the support of the US Department of Energy, the Office of Energy Efficiency and Renewable Energy, the Fuel Cells Technology Program through a subcontract from General Motors Corporation under grant DEEE0000470. 


\section{References}

(1) Eikerling, M. J. Electrochem. Soc. 2006, 153, E58-E70.

(2) Jung, C.-Y.; Yi, S.-C. Electrochem. Commun. 2013, 35, 34-37.

(3) Hall, D. B.; Torkelson, J. M. Macromolecules 1998, 31, 8817-8825.

(4) Dishari, S. K.; Hickner, M. A. Macromolecules 2013, 46, 413-421.

(5) Modestino, M. A.; Paul, D. K.; Dishari, S.; Petrina, S. A.; Allen, F. I.; Hickner, M. A.; Karan, K.; Segalman, R. A.; Weber, A. Z. Macromolecules 2013, 46, 867-873.

(6) Dishari, S. K.; Hickner, M. A. ACS Macro Lett. 2012, 1, 291-295.

(7) Paul, D. K.; Fraser, A.; Pearce, J.; Karan, K. ECS Trans. 2011, 41, 1393-1406.

(8) Siroma, Z.; loroi, T.; Fujiwara, N.; Yasuda, K. Electrochem. Commun. 2002, 4, 143145.

(9) Spry, D. B.; Goun, A.; Glusac, K.; Moilanen, D. E.; Fayer, M. D. J. Am. Chem Soc. 2007, 129, 8122-8130.

(10) Zawodzinski, T. A.; Springer, T. E.; Davey, J.; Jestel, R.; Lopez, C.; Valeria, J.; Gottesfeld, S. J. Electrochem. Soc. 1993, 140, 1981-1985.

(11) Paul, D. K.; Karan, K. J. Phys. Chem. C 2014, 118, 1828-1835.

(12) Choi, P.; Jalani, N. H.; Datta, R. J. Electrochem. Soc. 2005, 152, E123-E130.

(13) Ohira, A.; Kuroda, S.; Mohamed, H. F. M.; Tavernier, B. Phys. Chem. Chem. Phys. 2013, 15, 11494-11500.
(14) Modestino, M. A.; Kusoglu, A.; Hexemer, A.; Weber, A. Z.; Segalman, R. A. 2012.

(15) Spry, D. B.; Fayer, M. D. J. Phys. Chem. B 2009, 113, 10210-10221.

(16) Watson, V. J.; Saito, T.; Hickner, M. A.; Logan, B. E. J. Power Sources 2011, 196, 3009-3014.

(17) Holdcroft, S. Chem. Mater. 2014, 26, 381393.

(18) Kreuer, K. D. J. Mem. Sci. 2001, 185, 2939.

(19) Wu, X.; Wang, X.; He, G.; Benziger, J. J. Polym. Sci. B Polym. Phys. 2011, 49, 14371445.

(20) Asay, D. B.; Kim, S. H. J. Phys. Chem. B 2005, 109, 16760-16763.

(21) Watanabe, M.; Sanui, K.; Ogata, N.; Kobayashi, T.; Ohtaki, Z. J. Appl. Phys. 1985, 57, 123-128.

(22) Fayer, M. D.; Levinger, N. E. Ann. Rev. Anal. Chem. 2010, 3, 89-107.

(23) Paul, D. K.; Karan, K.; Docoslis, A.; Giorgi, J. B.; Pearce, J. Macromolecules 2013, 46, 3461-3475.

(24) Tielrooij, K. J.; Cox, M. J.; Bakker, H. J. ChemPhysChem 2009, 10, 245-251.

(25) Zulauf, M.; Eicke, H. J. Phys. Chem. 1979, 83, 480-486.

(26) Dokter, A. M.; Woutersen, S.; Bakker, H. J. Proc. Natl. Acad. Sci. USA 2006, 103, 15355-15358.

(27) Dura, J. A.; Murthi, V. S.; Hartman, M.; Satija, S. K.; Majkrzak, C. F. Macromolecules 2009, 42, 4769-4774. 